\title{
Using real-world cases, innovation and rhetorical tools to teach social pharmacy
}

\author{
Lotte Stig Nørgaard 1 (D), Mathias Møllebæk ${ }^{2}$ (D), Per Liljenberg Halstrø³ (iD), Nina Louise Fynbo Riis ${ }^{4}$ (D), \\ Vibeke Brix Christensen 5 iD, Lourdes Cantarero Arevalo ${ }^{1}$ \\ 1 Social and Clinical Pharmacy, Department Pharmacy, Faculty of Health and Medical Sciences, Copenhagen University, \\ Universitetsparken, Denmark \\ ${ }^{2}$ Copenhagen Centre for Regulatory Science, Department Pharmacy, Faculty of Health and Medical Sciences, Copenhagen University, \\ Denmark \\ ${ }^{3}$ Copenhagen School of Design and Technology (KEA), Denmark \\ ${ }^{4}$ Capital Region of Denmark, Center for HR \& Education, Gentofte Hospital, Denmark \\ ${ }^{5}$ Department of Pediatric and Adolescence Medicine, Rigshospitalet, Copenhagen, Denmark
}

Keywords
Course
Denmark
Innovation
Rhetoric
Social pharmacy
Youth

Correspondence
Lotte Stig Nørgaard
Department Pharmacy
Copenhagen University
Universitetsparken
Copenhagen
Denmark
lotte.norgaard@sund.ku.dk

Keywords

Denmark

Social pharmacy

Youth

\section{Correspondence}

Department Pharmacy

Copenhagen University

Copenhagen

lotte.norgaard@sund.ku.dk

\begin{abstract}
Background: Innovation refers to the process in which individuals or organisations transform ideas into novel products, services or processes. Pharmacy graduates are increasingly expected to have the competencies necessary to find innovative solutions to medicine-related challenges, particularly solutions addressing patient's need and societal aspects of medicine use. Objective: To describe and discusses the rationale, development, implementation and evaluation of the pharmacy course 'Contemporary Social Pharmacy' (CONSOC), and to summarise lessons learned. Methods: Several methods and models were used to develop, run and evaluate the course. The course examination consisted of a written report and an oral presentation and defence of the report. The course was evaluated through a student assessment questionnaire and oral and written feedback from case providers and the teachers. Results: Three selected case reports representing particularly innovative solutions are described. The student evaluations revealed that nine out of 14 course learning objectives were either fully or partly fulfilled, and that what students liked best from the course were the teamwork, the open discussions, the real-world cases and the innovation features. The teachers and case providers also found the course rewarding and extremely positive. Conclusion: Teaching innovation opens up new possibilities for educators and researchers. The CONSOC course introduced several novel components, but the increased complexity of the course also presented challenges to students and faculty alike.
\end{abstract}

\section{Introduction}

Pharmacy graduates are increasingly expected to have the skills and competencies necessary to find innovative solutions to medicine-related challenges, particularly solutions addressing the societal aspects of medicine use. The importance of taking a patient-centred perspective on the complexities of medicine use in society has been emphasised repeatedly (Lee et al., 2018; Sacristán 2014; University of Copenhagen, 2021a), and many argue that innovative approaches to these issues must be developed (Baregheh et al., 2009). Innovation generally refers to the process in which individuals or organisations transform ideas into novel products, services or processes.

Teaching innovation opens up new possibilities and challenges for educators and researchers. Although such teaching provides a framework for bringing research and academic teaching closer to real-world problems, it also 


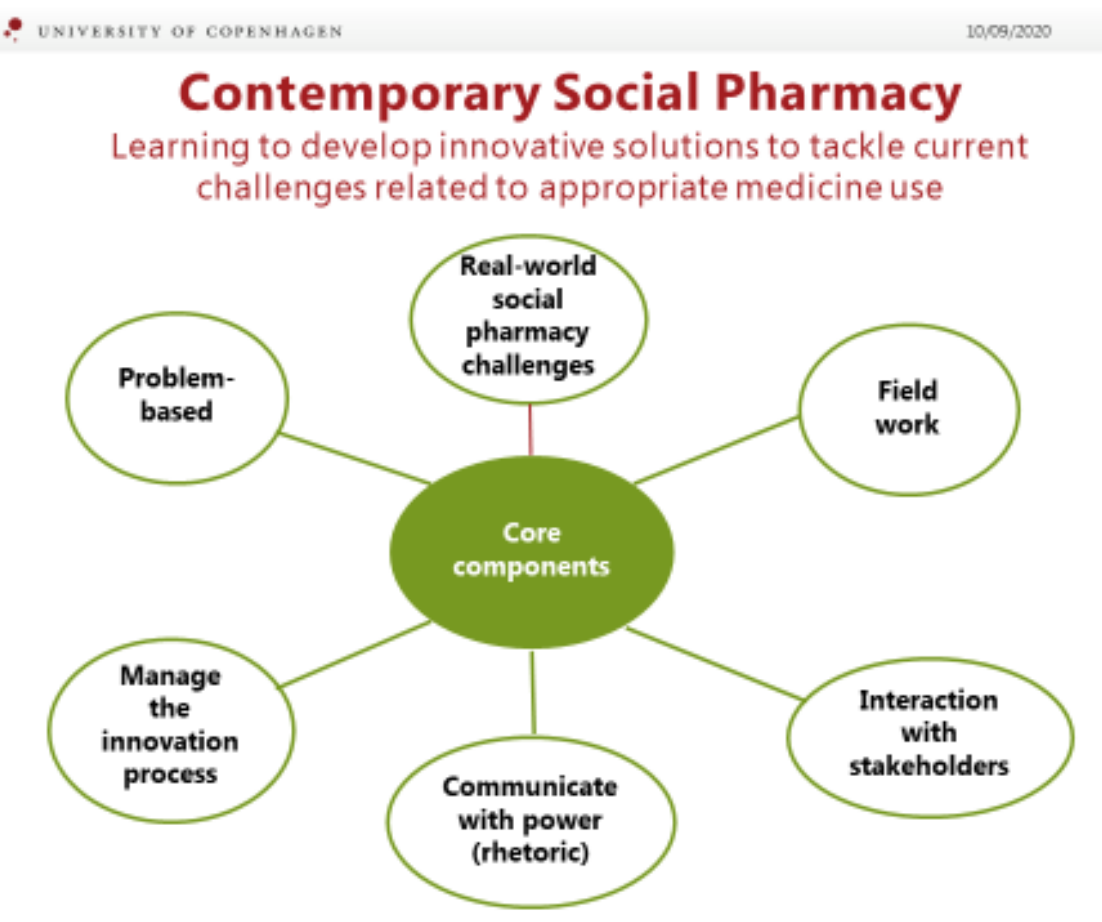

Figure 1: Contemporary Social Pharmacy (CONSOC) course core components

requires educators to develop new approaches to their teaching. Over the past five years, teachers at the University of Copenhagen having increasingly used innovation methods in their courses. This comes as a response to students' interest in enhancing their innovative and entrepreneurial skills and in learning in new ways through real-life challenges. More specifically, the university's Faculty of Health and Medical Sciences (HEALTH KU) utilise innovation and entrepreneurship experts to train and support teachers in incorporating innovation in their teaching. A networking unit has also been established to facilitate contact with healthcare professionals and provide real-world cases for students (Copenhagen Health Innovation, 2019).

The Social and Clinical Pharmacy (SCP) research group at HEALTH KU has been offering undergraduate students a social pharmacy course for the last three decades. Although the course content has changed over the years, the focus has always been on improving students' knowledge, skills and competencies in the societal aspects of medicine use. This long-term experience has shown the authors that their pharmacy students have difficulty grasping the political and societal complexities related to the use of medicines in society. This difficulty is understandable, as the bachelor curriculum includes no other social or political science courses. This motivated the authors to offer a hands-on course that uses real-world cases as a complement to existing courses.
In 2016, a group of researchers and teachers from the SCP group teamed up with experts in innovation, rhetoric and pedagogy to design a course that would allow students to work innovatively with real-world cases. This decision to go beyond problem-based to more innovation-based design was intended to motivate and empower students and boost their creative thinking skills. Consequently, the authors designed and implemented a course that helps students develop their ability to handle pharmaceutical challenges in society and that draws on approaches from innovation disciplines.

\section{Methods}

\section{Description of the course}

The aim of the course is two-fold: 1 ) to enhance students' understanding of contemporary social pharmacy via reallife challenges related to the rational use of medicine, and 2) to improve students' ability to work independently in teams (University of Copenhagen, 2020b). Other core course aims included raising students' competency level as regards interaction with stakeholders and equipping students with rhetorical tools to heighten their communication skills. Figure 1 provides an overview of the core course components, and Table I maps the course programme. 


\section{Table I: Course programme for the Contemporary} Social Pharmacy course (2018 and 2019)

\begin{tabular}{lll}
\hline Timeframe & Content & Activities \\
Week 1 & $\begin{array}{l}\text { General introduction to the cour- Lectures, presentations } \\
\text { se, social pharmacy, innovation and discussions } \\
\text { and rhetoric }\end{array}$ \\
Week 2 & $\begin{array}{l}\text { External actors' case presentations Presentations Q\&A } \\
\text { session }\end{array}$ \\
& $\begin{array}{l}\text { Teamwork OR introduction to Lectures and } \\
\text { selected social pharmacy issues for discussions }\end{array}$ \\
& $\begin{array}{l}\text { Master of Pharmaceutical Science } \\
\text { (MPS) students (in 2018). In 2019 }\end{array}$ \\
all students were introduced to \\
selected recent social pharmacy \\
research under the theme for the \\
year
\end{tabular}

The course is equivalent to seven and a half European Credit Transfer and Accumulation System (ECTS) credits (estimated student work load of 206 hours), and runs for three months altogether. It was first held in spring 2018 with 38 students and again with 58 students in 2019.

The course started with a short introduction to the basics of social pharmacy from an international perspective. In 2018, this introductory part was offered only to those students unfamiliar with social pharmacy because they came from other academic backgrounds (Master of Pharmaceutical Science (MPS) students - see Table I). In 2019, this introduction was offered to all course participants. Table II shows the course learning outcomes broken down by knowledge, skills and competencies, as set out in the course description (University of Copenhagen, 2020a).

\section{Course theme for the first two years: Medicines and Youth}

The topic 'Medicines and Youth' was chosen for the course in 2018 and 2019 because the two teachers (LCA and LSN)

\section{Table II: Learning outcomes for students following} the Contemporary Social Pharmacy course

Knowledge:
- Describe contemporary social pharmacy challenges within a
specific topic
Describe the actions applied so far to try to resolve the
identified challenges
- Identify key actors within the specific topic
Describe and discuss the different phases of an innovation
process addressing social challenges
Describe and discuss basic rhetorical principles of oral and
written professional communication that can support
the argument for change

Skills:

- Take responsibility for a small project on how to tackle contemporary social pharmacy challenges, at national or international level (conducted according to the principles and phases of an innovation process)

- Gain an in-depth understanding of the specific topic in place as part of this process

- Analyze the complexity of reasons for, and solutions to, identified challenges

- Argue convincingly for suggested solutions

Competencies:

- Work independently in groups and manage this work

- Work in a project-oriented, constructive way

- Analyze complex contemporary social pharmacy challenges

- Present innovative solutions to challenges in a convincing manner

- Identify one's own group's needs for supervision

heading the course were researching medicines use among adolescents and young people (Vestergaard et al., 2017; Petersen et al., 2018, Druedahl et al., 2018, Branquinho et al., 2020; Cantarero-Arévalo et al., 2016). This provides them with a network from which to identify and pick case providers, and they also expect the students' teamwork to influence their ongoing and planned research in the area of medicines and youth.

The external actors/case providers presented their specific cases or challenges by giving a 30-minute oral presentation in course week one or course week four (see Table I). Here the external actor described the background to his or her case and the case itself. LCA, LSN and/or MM had previously given the external actors a case description guide to help them define key aspects of their case and to ensure that the scope and complexity of the case problem did not exceed the course learning outcomes (see Table III). 


\section{Table III: Case provider guide for making a case description}

Case provider: [insert name of case provider]

1. Background

Please briefly sketch the background/context of the problem. What is the exigency of the case and whom does it affect?

\section{Problem}

Please describe the problem that you want the team to solve. Avoid outlining potential solutions.

3. Learning goals and case provider's expectations Describe the expectations you have for the students' end-product. The learning goals of the course relate to the student's understanding and analysis of the problem, process-oriented work and persuasive communication of the end-product.

4. Availability of case provider during the course Please indicate whether and to what extent you are available to students for questions during the course period.

\section{Innovation and rhetorical tools}

As the innovation field was new to most of the students, the course team decided to have sessions covering the following topics:

- Basic theories, models and mindset of innovation

- The art of asking questions and defining needs

- Idea generation, methods and teamwork

\section{Basic theories, models and mindset of innovation}

The first innovation workshop titled 'Innovation in 30 minutes' introduced the students to the basic theories and models of innovation, focusing on innovation drivers in a societal and political context (Christensen et al., 2004). The workshop aimed to give students a critical perspective on where demands for innovation originate. For example, does a patient/citizen-centred focus or a more political and managerial point of view underlie the urgency to develop new (and perhaps disruptive) solutions? This is an essential aspect for social pharmacists to bear in mind when developing an idea and even more so when managing implementation of the solution.

\section{Asking questions and defining needs}

The topic of how to ask questions and define needs was addressed during the subsequent innovation workshop, 'The Einstein Workshop.' Its name is based on the quote:
'If I had an hour to solve a problem I'd spend 55 minutes thinking about the problem and 5 minutes thinking about solutions.' [Albert Einstein]

The workshop focused on how students could ask questions to better understand the cases presented and on how to help students select a problem definition. This workshop centred on the idea that when trying to solve a problem, the authors often leap to the solution without spending much time trying to understand the case in depth. Coming up with solutions early in the process can narrow the students' approach, keeping them on one track and inhibiting them from viewing the problem/case in alternative ways.

\section{Idea generation, methods and teamwork}

Once the students had completed the introductory sessions, the case presentations and the innovation workshop, they expressed their preferences and prioritised the cases, and the course leaders started assigning cases (see below under 'Distribution in teams'). With the cases distributed and the teams formed, the students started to reflect on their cases and begin the idea generation phase. They were introduced to different idea generation methods via a sprint workshop inspired by Google's design sprint concept (Design Spirits, n.d.). The aim of the workshop was to introduce the students to as many innovation tools as possible and to UCPH's online innovation toolbox (University of Copenhagen, 2020b) where they could find inspiration and other methods and models. The students were introduced to the following models and definitions from the toolbox: convergent (zooming in) versus divergent (creative) thinking; the Design Thinking model; the Double Diamond model; the five Whys model; the bad ideas exercise; the Goal/Hero/ Helper tool; the ideation sprint; idea categorisation, dot voting; rapid conceptualisation; fail fast ('dirty and rapid prototyping'). In their casework, the students described, discussed and further used the Design Thinking model in particular (see Figure 2). Design thinking is a particularly suitable approach to solving complex problems where one must draw on knowledge from many academic disciplines to interpret and solve the problem.

The Double Diamond model (see Figure 3) was also presented, discussed and used extensively by the students afterwards. This process model is inspired by the professional design process that emphasises problem analysis as the basis for creating a solution for an external client. The model is particularly suitable for structuring a course that collaborates with external actors and involves 


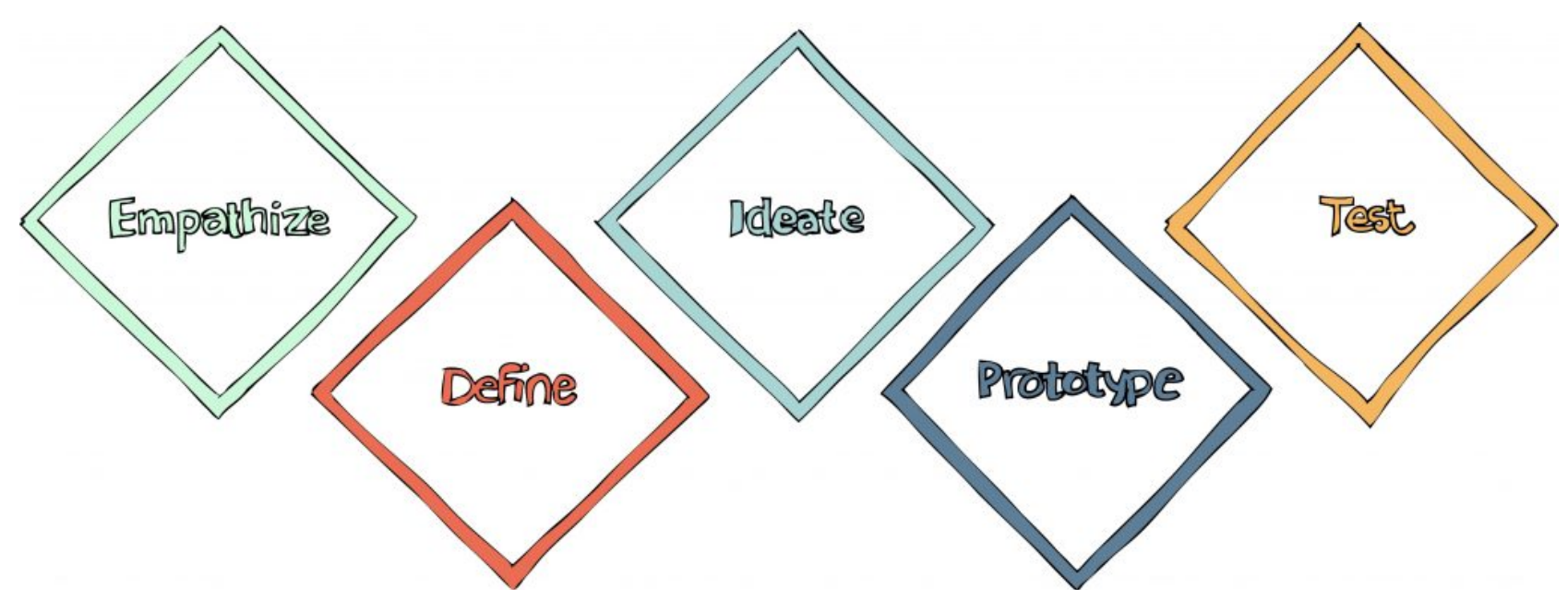

Figure 2: The Design Thinking model (University of Copenhagen, 2020b)

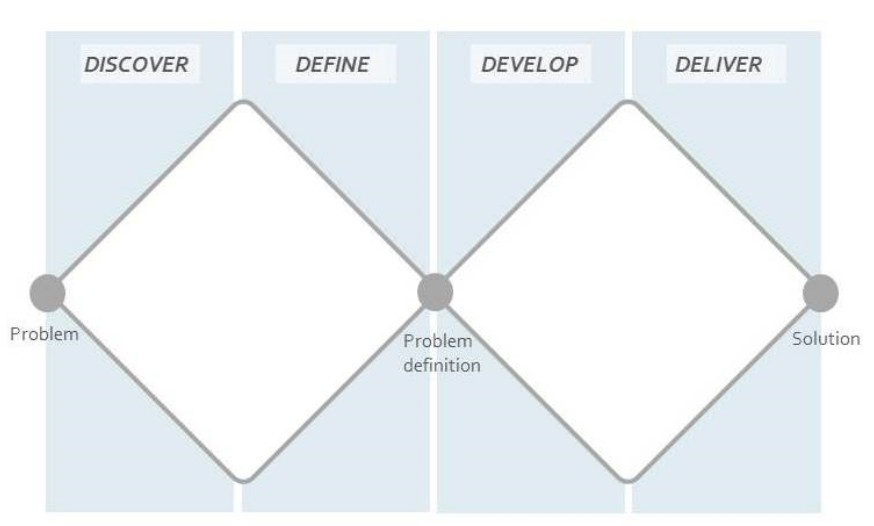

Figure 3: Double Diamond model (University of Copenhagen, 2020b)

users in developing solutions, as was the case for this course.

\section{Enhancing presentation skills with rhetorical tools}

The aim of introducing rhetoric and rhetorical modes of thinking to the students was two-fold: 1) to enhance their communication and presentation skills, and 2) to open them to new ways of thinking about and reflecting on the problem to be addressed, their new ideas and stakeholders' opinions and perceptions. This would support students not only in their present classwork, but also later in life because rhetorical modes of thinking allow people to understand and adapt to new contexts of communication. However, rhetoric is not merely the final verbal 'packaging' of content - the process of generating, organising and articulating ideas is equally central to rhetorical tradition (what is generally referred to as invention).
The students were introduced to and worked with the following communication/presentation techniques and models:

- Cicero's pentagram was introduced as a means of getting students to reflect on the situations in which they might eventually make a presentation (see Figure 4).

- Three modes of appeal. Ancient rhetoric introduced three modes of appeal: the speaker's personal character (ethos), the audience's emotions when being addressed (pathos) and the speech itself and arguments it presents (logos). The key takeaway in this context was that all three modes influence the reception of any presentation to varying degrees. For example, an exhaustive focus on logos appeals can make the speaker seem aloof and over-concerned with circumstances, and the audience may feel uninterested or unable to see the relevance. The key is to balance all three modes.

- The Hey-You-See-So-model. This simple heuristic organises a presentation into a sequence of four components that helps students balance the three modes of appeal: 'Hey' captures the audience's interest from the beginning, typically with a short story or an example; 'You' ensures that the relevance for the audience ('you') is explained; 'See' outlines the case and the arguments; and 'So' concludes the presentation by outlining implications and future decisions.

- The Ergasia model, a tool for discovering and amplifying arguments, was also introduced. This taught the students about how to add weight to their arguments for their designed solution (Halstrøm, 2017). The model is relevant because it teaches 
students to evaluate their ideas and choose between them by visiting and exploring the strengths of their arguments for them. It also teaches students how to persuade an audience.

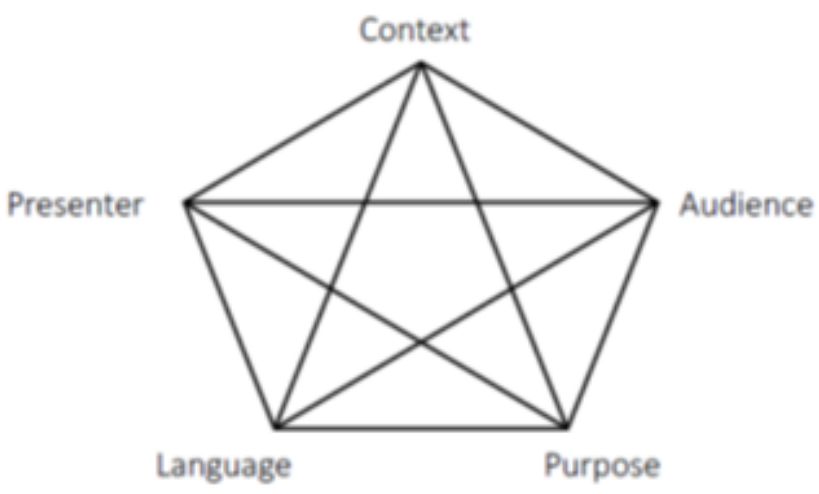

Figure 4: The rhetorical situation/Cicero's pentagram

\section{Distribution in teams}

After the weeks of general lectures, case presentations and lectures on rhetoric and innovation, the students were asked to prioritise three cases they would like to work with for the remainder of the study unit (two and a half months). The course leaders (LCA and LSN) then divided the students into teams of five or six and assigned one case to each team. Heterogeneously composed teams often establish the strongest knowledge base and typically produce more creative processes and solutions. Thus, the authors strove to make teams as diverse as possible. The authors, distribution criteria were to have all students work with one of his or her three case requests, to have bachelor and master students represented on all teams, and to have both Danish and foreign students on all teams.

\section{Alignment agreement: how to work together in a team}

Once the teams were formed, a team-building session was held. The innovation consultant (NLFR) in charge of this session used the Jung's Type Indicator (JTI) (Reynierse, 2012), which is a personality test that introduces the students to the strengths of different personal traits and preferences and how this can enhance teamwork.

An important element of teamwork is an initial common agreement on how to work together, the level of ambition, and the consequences when expectations are not met. Thus, the team's first task was to discuss and complete their own team charter/expectation alignment agreement. The team charter was meant to be a guide for the individual student and the team, and included questions on team visions and individual goals, execution and evaluation of team and individual member performances, work load and allocated time, decisionmaking and team management.

Besides team workshops on JTI and idea generation (for instance, students were introduced to and explored the four major groups of questions, as described by Karl Tomm (Tomm, 1988), the students received two to three sessions of supervision from members of the SCP research group both in 2018 and in 2019.

The students then started their research process, reading the scientific and grey literature, meeting with different actors relevant for their cases, and working with innovation tools. They started to develop an innovative solution to tackle the challenges embedded in their cases.

In the authors experience, case-driven teamwork can benefit from students observing and discussing how other teams tackle their cases. Therefore, the authors decided to hold a mid-term seminar where each team presented its case and how it was being handled. Each presentation was followed by a ten-to-15-minute dialogue between the course leaders, the teams and the rhetoric experts (MM or PLH). While peer feedback can be beneficial to givers and receivers, specific instructions on how to provide feedback are needed. This is why the authors introduced a set of guidelines for peer feedback at the beginning of the mid-term seminar. The authors encouraged students to be specific, constructive and kind, and to 'go for the ball - not the person', as described by the 'Sandwich' technique.

\section{Products and examination}

The course examination (pass/fail) was split in two: 1) the submission of an eight-to-ten-page report and 2) an oral presentation of the report and its subsequent defence. (See Table IV.) During the oral examination seminar each team had a maximum of 20 minutes to present the content of their report. Another group opposed the team (ten minutes), and the following groups then each had ten minutes to make comments: the external actor/case provider; the course leaders (LCA or LSN), the rhetoric teacher (MM or PLH) and the innovation consultant (NLR); and the remaining students. 


\section{Table IV: Case provider guide for making a case description}

Exam $\quad$ written product and an oral product describing the process
the team has gone through and arguing for the choice of
the team has gone through and arguing for the choice of innovative solution(s) to identified problems.

Written Exam To pass the written exam, the team has to submit an eight-toten page report containing:

- A description of problem background (i.e. the context of the selected problem) and its relation to the course topic: 'Medicines and Youth'

- A description of the selected problem and client expectations

- A description of initiatives/activities implemented so far to try to resolve the identified challenges

- A description of central actors who relate to the selected problem and reflections on how the team constructively interacted with them to gain an in-depth understanding of the problem and its background

- Reflections on communication aspects, namely preparation of the final presentation and the use of tools, e.g. structure and actantial model

- A description of the project process (including steps taken, challenges met, how they were met, timeline - anticipated and real/factual - and process evaluation)

- Descriptions and reflections on elements used from the innovative toolbox (convergence, divergence, etc), including a description of different phases of the innovation process

- A reference list

- Log book from the team work sessions that enables the reader to distinguish between each team member's activities and writings (independent work)

Oral exam

(evaluation seminar):

As part of the evaluation

seminar, all teams are to critique the work of another

team (ten

minutes):

\section{Products: Selected case report descriptions}

Table $\mathrm{V}$ provides an overview of the different cases presented to the students in 2018 and 2019. The following briefly describes three selected case reports that were submitted and defended by the students at the evaluation seminars. The case reports represent particularly innovative solutions and/or extensive use of the innovation and rhetorical models introduced in the course as perceived by the course team and the case providers.

\section{LGBTQ young men living with eating disorders}

A team worked with the following problem: How can the authors at an early stage identify this special group of LGBTQ young men living with an eating disorder (ED) and support them before they need hospitalisation and massive doses of anti-psychotic medicines? The student team used several of the innovation tools described above, namely 1) the Design Thinking model, 2) classic brainstorming with categories (see result in Figure 5) and 3 ) inspiration cards with words. The students had serious difficulty interviewing such key figures as people involved with Copenhagen Pride, young people admitted to hospital or members of the LGBTQ community. For this reason, instead of interviewing young LGBTQ persons with $E D$, the team listened to several YouTube videos where these young people described the challenges of being an LGBTQ person suffering from ED. These personal descriptions made the team realise the urgent need for an awareness campaign for LGBTQs, so it tackled the case from this angle. The awareness campaign was to be based on real-life stories; to include music, colour and light; to last for two to three minutes; to have a hashtag; to be uploaded and available on YouTube and Facebook; and not least to refer to help networks.

The team intended the campaign to be a wake-up call for society as a whole, as they felt that the suffering and struggles of this specific group were insufficiently recognised (for instance, of 1,000 LGBTQs, more than half had an ED diagnosis and almost $60 \%$ had had suicidal thoughts). At the evaluation seminar, where the students made use of the Hey-You-See-So model to present their product, the case provider was highly supportive of the idea of developing an awareness campaign that would seriously address the struggles of this community and grasp the lifestyle at stake.

\section{Adolescent reproductive health - a global perspective}

Another student team chose to work on an initiative in the hope of helping increase adolescents' use of contraceptives in Ghana, a country with an extremely low rate of contraceptive use and a high prevalence of teen pregnancy. The team used the following innovation tools: 1) stakeholder analysis, 2) brain walking, 3) classic 
Table V: Case providers, subtopics/cases and problem

\begin{tabular}{lll}
\hline Year & $\begin{array}{l}\text { Case provider } \\
\text { (position and affiliation) }\end{array}$ & Case \\
\hline 2018 & $\begin{array}{l}\text { Medical doctor, head of the Adherence to medicines } \\
\text { Center of Adolescent Health, }\end{array}$ & $\begin{array}{l}\text { How can we support adolescents' identity and growing independence and at the } \\
\text { Rigshospitalet, Copenhagen }\end{array}$
\end{tabular}

Rigshospitalet, Copenhagen Capital Region

2018 and Medical doctor, Rigshospitalet, Misuse of medicines with PMC is easy to obtain. Does not taste bad. Suicide attempts with PMC are often a over-dose (PMC)* fits-all'.

2018 Anthropologist, University of 'Study drugs' (SD) use Southern Denmark

Lack of knowledge in the following areas: cross-cultural comparison of attitudes, acquisition and/or use of SDs; the role of the internet; psychiatrists' attitudes and prescribing practices in Denmark; SD users seeking help.

2018 and Danish College of Pharmacy Young customers at the Who purchases medicine for chronic illnesses, who purchases OTC painkillers and 2019 Practice community pharmacy who has skin problems?

2018 Leo Innovation Lab

Difference in user behavior How can passive collection be leveraged to improve research?

following passive data collection How can it be used to improve the patient's adaption of a treatment (in terms of both adherence and dosage)?

2018 Parent of an adolescent living Patient perspective (psychiatry) How to improve the treatment and life quality of young people with anxiety. with affective disorders

2019 Senior Researcher, Steno Type 1 diabetes - emerging As autonomy increases, the diabetes management roles and responsibilities of preDiabetes Center Copenhagen teenagers, pre-teenagers and teenagers and their parents change. Parents often decrease their direct involvement emerging adults in diabetes care tasks and increase their expectations for adolescents' diabetes management. This poses new challenges to treatment adherence.

2019 Nurse, psychiatric center, Eating disorder-LGBTQ* Copenhagen

How can we identify this special group of patients at an early stage, before they need hospitalisation and long term use of anti-psychotic medicine? Find an antidote to the potential factors pointed out by the National Eating Disorders Association

Paediatrician, Child and IBS and mental health/legal Insufficient treatment adherence to long-term medical treatment is frequent in this Adolescent Health Depart- rights age group, and the combination of physical and mental health issues might ment, North Zealand Hospital Young patients living with both exacerbate the problem.

physical and mental illness

Medical doctor, consultant, Sexual and reproductive health How would you design a program in a low-income country (you may choose a former WHO employee $\quad$ services* specific country if you wish) for increasing access to and use of adolescent sexual and reproductive health services, including access to contraceptives, and for addressing one or more of the barriers?

Would the approach be different for boys and girls?

How would you involve the adolescents themselves?

Would you involve other actors?

\footnotetext{
* means that a case report submitted by one of the student teams is described below under Selected case report descriptions
}

brainstorming and 4) confusion tolerance exercise - all were embedded in the Design Thinking model (see Figure 6).

The team chose to base their proposed solution on improving adolescents' knowledge by further developing an educational television (TV) series entitled 'YOLO' to optimise its impact. The TV series has been running since 2015 and deals with adolescent sexual and reproductive health by addressing everyday problems such as peer pressure, unprotected sex, relationship issues, and deprived versus wealthy backgrounds. Research had shown that adolescents watching the series were much more knowledgeable about reproduction and sexually transmitted diseases than non-watchers. In their report and during the evaluation seminar, the team explained how they would optimise YOLO by making the series interactive, using voice-overs to bring it to foreign audiences, and connecting a text message service to the series in which viewers could ask questions while watching 


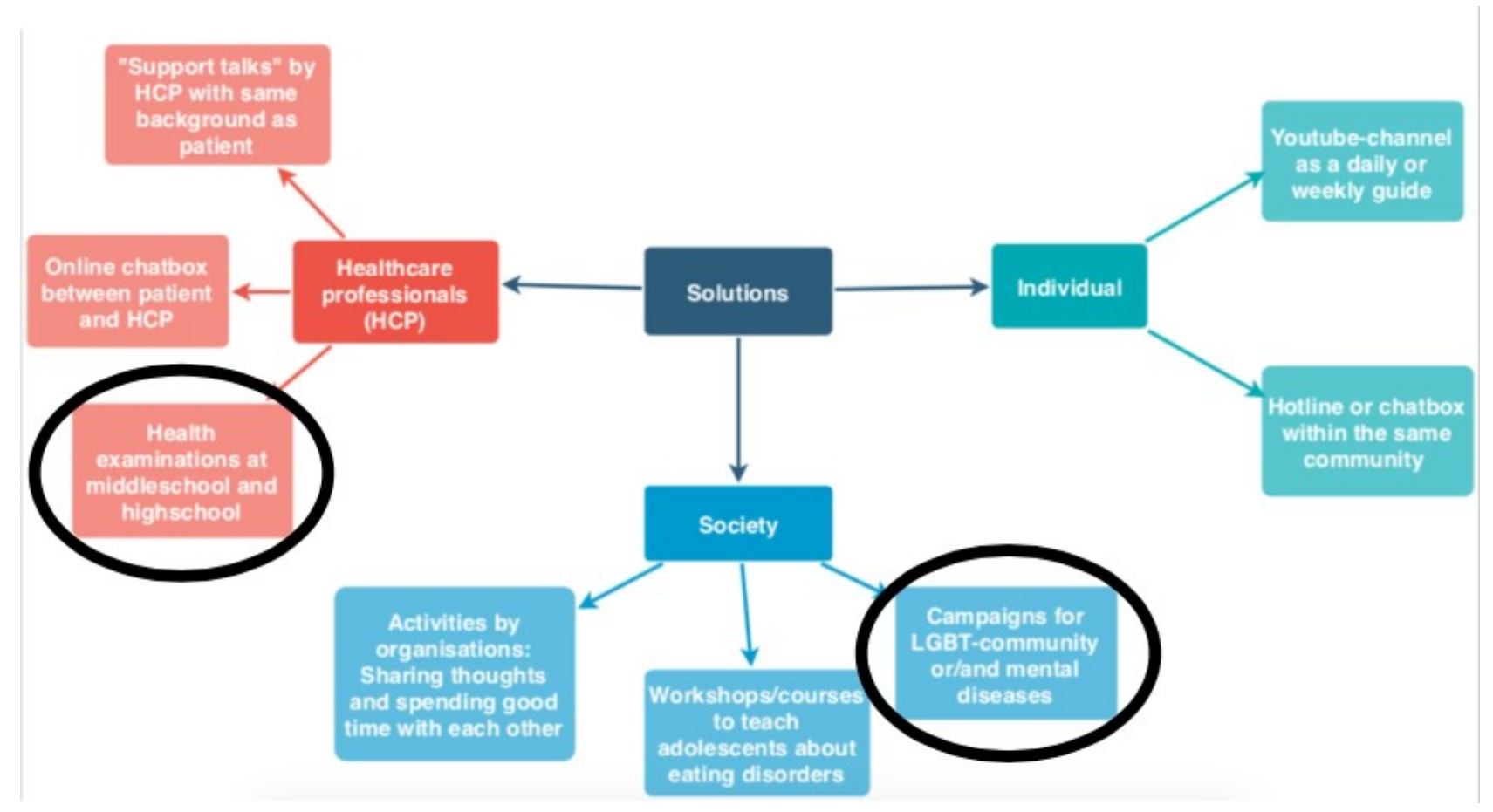

Figure 5: Categorised idea map developed from using the innovation tool 'inspiration cards with words'

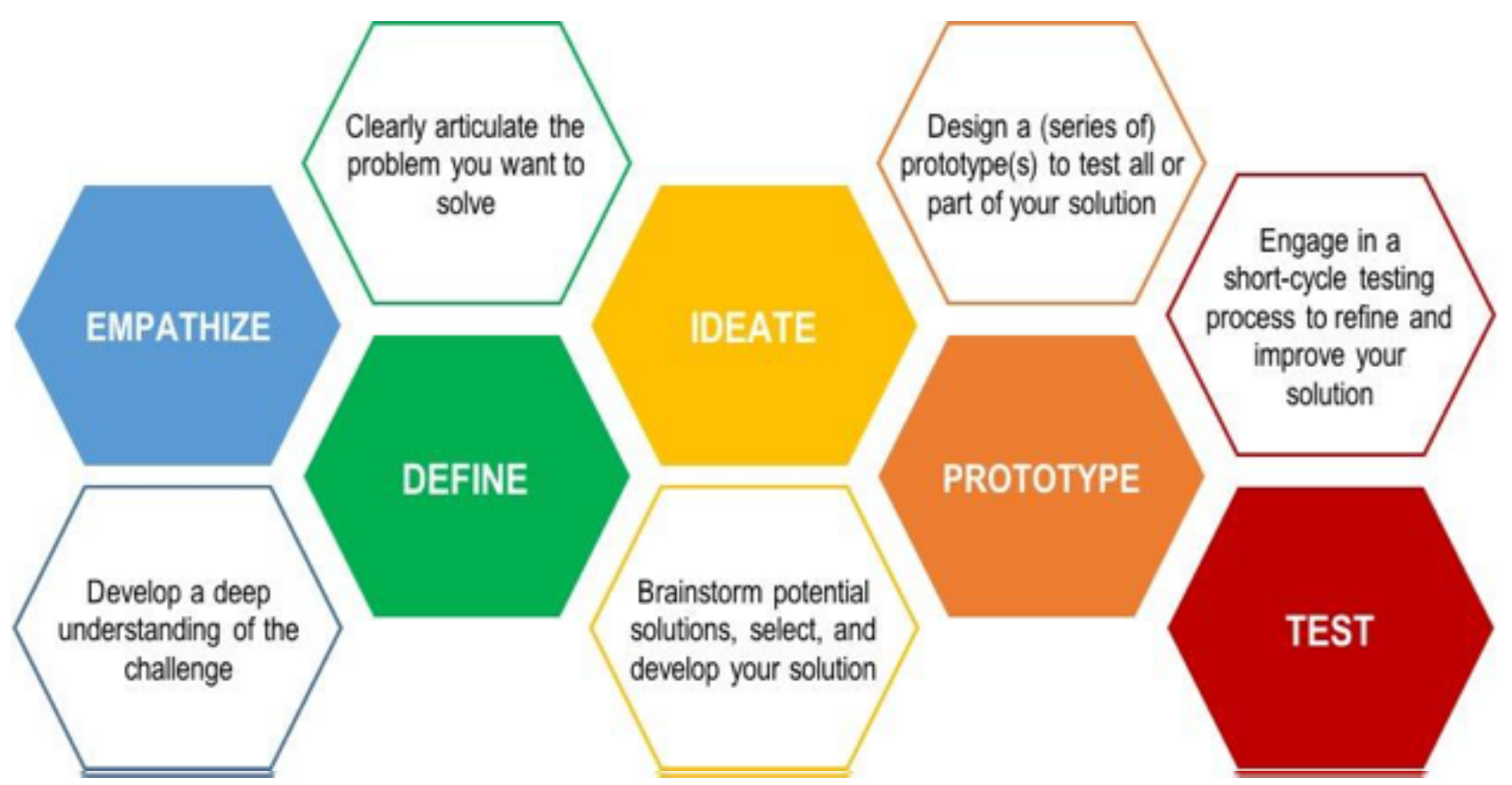

Figure 6: The Design Thinking model used by the team 
the series. Other components included screenplay writing, how to seek funding, and how to try out prototypes and conduct tests through a youth panel. The team used the Hey-You-See-So model at the evaluation seminar and got positive feedback from the case provider.

\section{Paracetamol overdose case}

Suicide was the second leading cause of death among 1529-year-olds globally in 2015. Every suicide is a tragedy that affects families, communities and entire countries, and has long lasting effects on those left behind. The number of suicide attempts among adolescents is on the rise. Paracetamol (acetaminophen) is often suicidal young women's drug of choice (Hawton et al., 2003; Hedeland et al., 2013). An overdose results in toxic damage to the liver, which may require transplantation. The only treatment options open to a pediatric hepatologist are to admit the patient, start $\mathrm{N}$-acetylcysteine infusion and evaluate the need for a transplantation. The treatment is expensive and a poor solution in the long run, as a shortage of donor organs may lengthen the waiting list for liver transplants. In addition, young women who overdose on drugs might not get psychological help and thus make another attempt. More sustainable solutions are therefore needed.

Two teams worked with this case, both in 2018 and again in 2019, all taking different approaches. Three teams interviewed the case provider at the hospital and accompanied medical staff on a clinical round at the semiintensive care unit and the outpatient clinic. All teams came up with new ideas such as having a questionnaire about suicide on social media, conducting focus groups, organising theme days at primary schools and engaging influencers to inform teenagers of the risk of overdosing with acetaminophen. The case provider (VBC) wrote in her concluding mail to the course leaders:

'It was deeply inspiring to present the case and the dilemmas to the students. Some of their ideas have changed the authors communication and clinical handling of suicide attempts with acetaminophen, so there has been a change for the better.'

The authors found the students' work rewarding for the students, the case providers and us as teachers. The case providers responded that, while some of the groups may not have come up with a solution they would implement, they still found it rewarding to hear the students' input. Some teams found a new way of viewing the problem, others discovered new information about the users, and yet others showed alternative ways of solving the issues with which the case providers were struggling. The authors would like to stress that, although the case providers may not have reaped the same benefits attainable from an agency, namely an easily implementable solution, they nonetheless got fresh perspectives and alternative ways of perceiving their work and of working with the problem.

For the students, the benefits are the insights they gain into real, complex problems they may later run into; the new perspective they get on their potential future profession; and the ability they obtain to look for theories that can help them solve their problems instead of always sticking to a prescribed reading list from their professors. In many cases they even discovered that they had more potential than they thought, meaning that they might not have considered themselves creative thinkers prior to the course, but experienced that creative thinking can also be taught and learned and is not only an inherent ability possessed by a select few.

\section{Results}

Assessing creative and innovative thinking is not as straightforward as assessing knowledge-based learning outcomes. As such, solely traditional forms of assessment cannot be used to effectively measure innovative thinking and the ability to present novel ideas (Cain, 2016). Other criteria such as authenticity, practicality and impact must also serve as guidance points for the assessment (Chapelle, 2007). Thus, the course was evaluated through a combination of various data sources, such as an assessment questionnaire based on students' learning outcomes, internal team evaluation (data not presented below), oral and written feedback from case providers (both on the written report and the presentation).

\section{Students' evaluation}

In 2018, the course leaders ran an online Sendstep-based evaluation with the participating students after the exam seminar. The students were given 15 minutes to fill out the online questionnaire, and after a short break the results were shown to all students and discussed in a plenary session. The students assessed whether each of the 14 learning outcomes had been fulfilled (yes, no, partly), and were also asked to qualitatively write down the three things they liked best about the course and three suggestions for improvement (see Table VI).

Table VI shows the result of the self-assessment on achievement of learning objectives. Nine out of 14 learning objectives were either fully or partly fulfilled. The 
Table VI: Results of the self-assessment questionnaire on achievement of learning objectives $(N=29)$

\begin{tabular}{|c|c|c|c|}
\hline $\begin{array}{l}\text { Having completed the Contemporary } \\
\text { Social Pharmacy course in } 2018 \text {, can } \\
\text { you ... }\end{array}$ & $\begin{array}{l}\text { Yes } \\
\text { n (\%) }\end{array}$ & $\begin{array}{l}\text { No } \\
\text { n (\%) }\end{array}$ & $\begin{array}{l}\text { To some } \\
\text { extent } \\
\text { n (\%) }\end{array}$ \\
\hline $\begin{array}{l}\text { Describe contemporary social pharm- } \\
\text { acy challenges within a specific topic? }\end{array}$ & $18(60.7)$ & 0 & $11(39.3)$ \\
\hline $\begin{array}{l}\text { Describe the activities applied so far } \\
\text { to try to resolve the identified } \\
\text { challenges? }\end{array}$ & $25(84.6)$ & $2(27.7)$ & $2(7.7)$ \\
\hline $\begin{array}{l}\text { Identify key actors within the specific } \\
\text { topic? }\end{array}$ & $23(80.6)$ & 0 & $6(19.2)$ \\
\hline $\begin{array}{l}\text { Describe the different phases of an } \\
\text { innovation process? }\end{array}$ & $17(59.3)$ & 0 & $12(40.7)$ \\
\hline $\begin{array}{l}\text { Describe the basic rhetorical principles } \\
\text { of oral and written professional } \\
\text { communication? }\end{array}$ & $16(53.8)$ & $1(3.9)$ & $12(42.3)$ \\
\hline $\begin{array}{l}\text { Assume responsibility for a small } \\
\text { project on how to tackle contemporary } \\
\text { social pharmacy challenges (conducted } \\
\text { according to the principles and phases } \\
\text { of an innovation process)? }\end{array}$ & $22(76.9)$ & 0 & $7(23.1)$ \\
\hline $\begin{array}{l}\text { Interact with different actors in a } \\
\text { constructive way to gain an in-depth } \\
\text { understanding of the specific topic in } \\
\text { question? }\end{array}$ & $21(72.0)$ & 0 & $8(28.0)$ \\
\hline $\begin{array}{l}\text { Analyze the complexity of reasons for, } \\
\text { and solutions to, the identified } \\
\text { challenges (and to suggest solutions } \\
\text { not previously carried out)? }\end{array}$ & $14(48.1)$ & 0 & 15 (51.9) \\
\hline $\begin{array}{l}\text { Argue convincingly for suggested } \\
\text { solutions? }\end{array}$ & 22 (76.9) & $1(3.9)$ & $6(19.2)$ \\
\hline Work independently? & 24 (81.5) & $2(7.4)$ & $3(11.1)$ \\
\hline Work in a project-oriented way? & 27 (92.2) & 0 & $2(7.7)$ \\
\hline $\begin{array}{l}\text { Work according to multi-disciplinary } \\
\text { principles, i.e. interact with different } \\
\text { actors such as other healthcare } \\
\text { professionals, patients, politicians, in a } \\
\text { constructive way? }\end{array}$ & $22(73.1)$ & $1(3.9)$ & $7(23.1)$ \\
\hline $\begin{array}{l}\text { Analyse complex contemporary social } \\
\text { pharmacy challenges? }\end{array}$ & $18(61.5)$ & 0 & $11(38.5)$ \\
\hline $\begin{array}{l}\text { Present innovative solutions to } \\
\text { challenges in a convincing way? }\end{array}$ & $20(69.2)$ & 0 & (9) 30.8 \\
\hline
\end{tabular}

learning objective concerning whether students were now able to analyse the complexity of reasons for and solutions to the identified challenges got the lowest rating.
The course aspects the students liked best were the teamwork, the open discussions, the real-world cases and the innovation features. The students mentioned:

'getting out of my comfort zone' and 'having to rely on the authors creativity rather than hard info'

as the most positive aspects. One student wrote:

'[The] knowledge I got from it, the people I got to know during the course... And the final sandwich'

as the three most positive things from the course.

The student's suggestions for improving the course included a desire for more concrete teaching in social pharmacy issues and for better instruction in how to maintain a problem definition mode for a longer time, since, as a student responded:

\section{'...pharmacy students are trained to find a quick solution'}

Besides, it was difficult for them to 'shift gear' mentally. The latter was especially relevant for the bachelor students, who faced considerable time pressure as they had to write their bachelor theses while taking part in the course. The course leaders took these suggestions into account, incorporating changes in the following years (2019 and 2020) by giving students more time to define problems, offering more social pharmacy teaching and harmonising submission deadlines with the bachelor project.

\section{Teachers' evaluation}

In both 2018 and 2019, during and after the course the two course leaders (LCA and LSN) had oral and written dialogues concerning the running and development of the course with the teachers (including VBC, MM, PLH, NLFR), the supervisors and the case providers.

To evaluate whether and how students embraced and made use of the different innovation and rhetorical models taught at the course, the innovation consultant (NLFR) and the two rhetoric teachers (MM and PLH) gave oral feedback on students' midway pitches, their final reports, their presentations and their innovation processes and products. Further, in 2019, the rhetoric teacher also provided specific written feedback on all 12 reports submitted.

All the many ongoing dialogues during planning, in breaks and after the course between course leaders (LCA and LSN), the two rhetoric teachers (MM and PLH) and the innovation consultant (NLFR) resulted in several evaluative remarks. Jeffrey Phillips, who has led several innovation 
projects and authored the book 'Make Us More Innovative' has suggested the following criteria be used to assess an innovation training programme: 1) view innovation as a process rather than a deep focus on one tool or technique; 2) use experienced instructors with practical innovation experience as well as training experience; 3) make use of active, hands-on training taught in a workshop style; and 4) build on and be familiar with a wide body of knowledge from a range of experts) (Phillips, 2021). We did all this at the authors course, but have nonetheless drawn up a list of what the authors found challenging - and to some extent still do when conducting such an innovative course for pharmacy students (from different backgrounds):

- Socialisation among students was a benefit but also a challenge, as it required students to engage on a more personal level than they were used to.

- The assessment of students' reports was challenging. The criteria for academic work differ from the more practical and utility-based criteria of innovation. For example, being thorough is an academic virtue but 'fail fast' is a mantra in innovation circles. In the most recently held course, a set of criteria from responsible research and innovation literature was adapted.

- $\quad$ Students were introduced to the assessment criteria in both courses. This was done in the interests of transparency, but also to some extent to provide a transparent strategy for the assessment process as a whole. The fact that all stakeholders provided comments at the exam seminar surely made the assessment more robust.

- At times, it was difficult to run the course with such a large and heterogenous group of students ranging from pharmacy bachelors to international students taking the master's programme in pharmaceutical science but who had never been exposed to social pharmacy theories and methods prior to joining the course.

- Dealing with a large group was challenging. Creative thinking implies sharing personal approaches and ideas, and this challenged some students, especially the less experienced.

- Participation in the course was mandatory for a number of students. This meant the levels of motivation and engagement varied, which some students occasionally found frustrating. In addition, some students had difficulty fully understanding the multidisciplinary nature - and thus the complexity of social pharmacy challenges while also having to learn about innovation tools, communication skills and teamwork.

- $\quad$ Staying in problem definition mode for an extended period and fully embracing 'fail fast' was a great challenge for pharmacy students, as their traditional natural science background typically pushes them to find the 'right' solutions and swiftly answer questions requiring a yes or no response.

Fortunately, the course was also rewarding and extremely positive in so many ways. The following are some of the positive ripple effects - some intended, others not - as the authors perceived them:

- The students assessed the course very positively and highlighted its novelty. For instance, the course leaders were asked to share their experiences during the department's Research Day in 2019 and at the university's Pedagogical Day in 2019.

- In 2019, the study board also selected the course to be one of two so-called inspirational courses that could serve as models for other courses.

- In November 2018, the course was presented at a workshop during the Copenhagen Health Innovation Conference, attended by 400 persons.

- In 2018, the two course leaders (LCA and LSN), the innovation consultant (NLFR) and the rhetoric teacher (PLH) were invited on a three-day study trip on how innovation courses are run in Freiburg and Zürich, together with other teachers from the University of Copenhagen already teaching innovation and entrepreneurship.

- Two students who passed the course in 2019 later won an innovation prize, and several others are now involved in innovation projects in the SUND Innovation Hub (University of Copenhagen, 2021b).

- The number of students attending the course almost doubled from 2018 to 2019.

- The course leadership changes every other year. In the long run, the course will thus involve all SCP teachers and researchers, thereby giving them all innovation and rhetoric qualifications.

- Most of the case providers were highly satisfied with the different team solutions.

\section{Future plans}

The It is the authors hope that all the ripple effects intended and unintended, positive and negative - will 
inspire other teachers who want to develop and implement a course with an innovation and rhetoric angle. We have 11 general recommendations for those looking to run a course like this:

- Choose real-life cases that are aligned with your research priorities. This will benefit and expand your research portfolio and allow you to supervise students better.

- Choose case providers who can be available to a reasonable degree to communicate with the course leaders as well as to engage and support the students during the innovation process.

- Choose cases that are suitable for innovation, not only for reflection. This subtle difference is important. An innovation consultant can be of great help in formulating a case that is suitable for this purpose.

- Start with a sort of bootcamp where students get to know each other as well as the various teams' individual and collective strengths and blind spots.

- If possible, make this type of course fully elective and as heterogeneous as possible. Students from different backgrounds will propel the innovation process.

- As course leaders, be transparent and open with colleagues, case providers and students about your decisions and working methods.

- Concentrate team-building activities, case presentations and social pharmacy lectures at the beginning in order to leave enough time for teamwork.

- Encourage the 'fail fast' and 'love the problem not the solution' attitudes as much as possible. Encourage students to gain their own experience and make mistakes, and run 'fuck-up' sessions where they can share their dead-ends in an environment with plenty of humour.

- Encourage students to use innovation tools as much as possible. Run 'play dates' where different toolboxes are tested.

- Include a long-term evaluation to find out if students actually benefited from this course during their professional life and if so, how.

\section{Conclusion}

The CONSOC course sets out to address several key issues in pharmacy education: the need to introduce and engage students in real-life problems with medicines; the need for students to learn how to communicate effectively; the need to acquaint students with innovative work processes and their role in social medicines issues; and the need for students to acquire that understanding through direct concrete experiences with real-life stakeholders. Although evaluations from students and the external actors who provided cases were generally very positive, important issues were raised, and some development work remains. The focus on real-life cases approached through innovation and rhetoric in a teamwork setting resonated with students because it allowed them to engage directly with issues regarding medicine use in society, and to do so in conversation with peers while simultaneously developing skills relevant for prospective jobs. However, compared with more conventional academic courses, the CONSOC course introduced several novel components, and the increased complexity of the course presented challenges to students and faculty alike. As most students were enrolled in other pharmacy courses at the same time, they needed to juggle stringent biomedical research and outside-the-box innovation, which some found difficult and stressful. For faculty, assessing progress and end-products was difficult because it diverged from standard academic assessments and the students' expectation of such assessments. Nonetheless, for the students' part, the increased complexity of the course reflects the multidisciplinary reality of contemporary pharmacy, and as such prepares them for a future in which they will have to address the need to think innovatively, combining their biomedical background with the experiences of the patients with whom they engage.

Working on finding innovative solutions to real-life problems introduced by pharmacists, doctors or patients was found to be a good way to strengthen students' understanding of the multidisciplinary complexities of medicine use, as well as to link their learning process with professionals/case providers who could inspire them. The professionals also participated in supervising and evaluating students' deliverables (report, presentation and defence), and the authors believe this component made the course design even more attractive and relevant for the students. Another aim was for students to incorporate an ethical dimension in their proposed solutions. This proved easier when patients were included as case providers. Finally, the opportunity to align the course with ongoing research projects at SCP allowed the research group members to realise a long-held ambition to achieve 
interaction and synergy between their research portfolios and their teaching duties.

\section{Acknowledgments}

Thanks to colleagues in the SCP group for commenting on an earlier version of this paper, and a special acknowledgement to the 10 case providers and the 96 students who took the course in 2018 and 2019.

\section{Declaration of interests}

None to declare.

\section{References}

Baregheh, A., Bowley, J., \& Sambrook, S. (2009). Towards a multidisciplinary definition of innovation. Management Decision. 47 (8), 1323-1339. https://doi.org/10.1108/00251740910984578

Branquinho, C., Kelly, C., Arevalo, L. C., Santos, A., \& Gaspar De Matos, M. (2020). 'Hey, the authors also have something to say': A qualitative study of Portuguese adolescents' and young people's experiences under COVID 19. Journal of Community Psychology, 48(8), 2740-2752. https://doi.org/ 10.1002/jcop. 22453

Cain, J. (2016). A Pharmacy Elective Course on Creative Thinking, Innovation, and TED Talks. American Journal of Pharmaceutical Education. 80 (10), Article 170

Cantarero-Arévalo, L., Perez Vicente, R., Juarez, S.P., \& Merlo, J. (2016). Ethnic differences in asthma treatment among Swedish adolescents: A multilevel analysis of individual heterogeneity. Scandinavian Journal of Public Health, 44(2), 184-194. https://doi.org/10.1177/1403494815614749

Chapelle, C.A. (2007). Challenges in Evaluation of Innovation: Observations from Technology Research. International Journal of Innovation in Language Learning and Teaching, 1(1), 30-45, https:// doi.org/10.2167/illt041.0

Christensen, C.M., Anthony, S.D., \& Roth, E.A. (2004). Seeing What's Next: Using Theories of Innovation to Predict Industry Change. Harvard Business School Press.

Copenhagen Health Innovation (2019). Collaboration Health Innovation Toolbox (СОВOX) (online). Available from: https://cobox.dk/en/aboutcobox/

Design Spirits. (n.d.). Design Spirit Methodology (online). Available from: https://designsprintkit.withgoogle.com/methodology/overview

Druedahl, L.C., Yaqub, D., Nørgaard, L.S., Kristiansen, M., \& CantareroArevalo, L. (2018). Young Muslim Women Living with Asthma in Denmark: A Link between Religion and Self-Efficacy. Pharmacy. 6(3). https://doi.org/10.3390/pharmacy6030073
Halstrøm, P.L. (2017). Rhetorical Tools for Discovery and Amplification of Design Arguments. Design Issues. 33(1), 3-16.

Hawton, K., Simkin, S., \& Deeks, J.D. (2003). Co-proxamol and suicide: a study of national mortality statistics and local non-fatal self-poisonings. British Medical Journal, 326 https://doi.org/10.1136/bmj.326.7397.1006

Hedeland, R.L., Jørgensen, M.H., Teilmann, G., Thiesen, L.R., Valentiner, M., Iskandar, A., Morthorst, B., \& Andersen, J. (2013). Childhood suicide attempts with acetaminophen in Denmark: characteristics, social behaviour, trends and risk factors. Scandinavian Journal of Public Health, 41(3):240-6. https://doi.org/ 10.1177/1403494812474122

Lee, J.L., Gurses, A.P., Kim, J.M., Suarez-Cuervo, C., Brown, R., \& Xiao, Y. (2018). Towards a More Patient-Centered Approach to Medication Safety. Journal of Patient Experience, 5(2), 83-87.https://doi.org/ $10.1177 / 2374373517727532$

Petersen, M. A., Øllgård, J.L.D., \& Nørgaard, L.S. (2019). Contextualizing Study Drugs - An exploratory study of perceptions and practices among study counselors, general practitioners, psychiatrists and from student polls. Research in Social and Administrative Pharmacy, 15(10), 1204-1211. https://doi.org/10.1016/j.sapharm.2018.10.005.

Phillips, J. (2021). How to Assess an Innovation Training Program (online). Availabele from: https://innovationmanagement.se/2013/06/12/how-toassess-an-innovation-training-program/

Reynierse, J.H. (2012). Toward an Empirically Sound and Radically Revised Type Theory. The Journal of Psychological Type: 72(1).

Sacristán, J.S. (2013). Patient-centered medicine and patient-oriented research: improving health outcomes for individual patients. BMC Medical Informatics and Decision Making. 13(6). http:// www.biomedcentral.com/1472-6947/13/6.

Tomm, K. (1988). Interventive interviewing: Part III. Intending to ask lineal, circular, reflexive and strategic questions? Family Process, 27, 115.

University of Copenhagen (2020a). Course description for 'SFAB20038U Contemporary Social Pharmacy' (online). Available from: https://kurser.ku.dk/course/sfab20038u/2020-2021.

University of Copenhagen (2020b). Innovation toolbox (online). Available from: https://innovationenglish.sites.ku.dk/contact/

University of Copenhagen (2021a). The WHO Collaborating Center for Research and Training in the Patient Perspective on Medicines Use (online). Available from: https://whocc-meduse.ku.dk/

University of Copenhagen. (2021b). SUND Innovative Hub - where students test ideas in practice (online). Available from: https:// sundhub.ku.dk/sund-hub-uk/

Vestergaard, S., Nørgaard, L.S., Traulsen, J.M., \& Kaae, S. (2017). Pharmacy Interns' Perception of Their Professional Role. American Journal of Pharmaceutical Education. 81 (1), 10. https://doi.org/10.5688/ ajpe81110 